\title{
Histogram Method for Determining the Location of the Internal Dump in Coal Open Pits
}

\author{
Alexei Selyukov ${ }^{1, *}$, Tatiana Gvozdkova ${ }^{2}$, and Juraj Janocko ${ }^{3}$ \\ ${ }^{1}$ T.F. Gorbachev Kuzbass State Technical University, Department of open pit mining, 650000 \\ Kemerovo, 28 Vesennya st., Russian Federation \\ ${ }^{2}$ T. F. Gorbachev Kuzbass State Technical University, Mezhdurechensk branch, 652881, 36 \\ Stroiteley st., Mezhdurechensk, Kemerovo region-Kuzbass, Russia \\ ${ }^{3}$ Technical University Košice, Faculty BERG, Letná 9, 04001 Košice, Slovakia
}

\begin{abstract}
With the deepening of open pit mining, the volume of worked out space increases and, along with it, the potential capacity for storing overburden. At the same time, the pits completely allocated for the internal dumps are used only by the end of the period of the open pit operation. The known theoretical approaches to determining the location of the internal dump are little implemented in the practice of surface mining, which is explained by two reasons. First, standard design solutions are based on wellknown theoretical provisions; secondly, a formalized template approach to substantiating certain design developments in the field of dumping of internal dumps prevails, which pushes them towards their fragmentary rather than integrated implementation. With regard to the conditions of the Kuzbass open-pit mines, the article proposes a modernized interpretation for the formation of structural schemes of the sequence of quarry fields on the basis of constructive-and-parametric studies of a multivariate adaptation of the internal dumping mode.
\end{abstract}

\section{Introduction}

Over the past twenty years, the volume of coal production in Kuzbass (Western Siberia, Russia) - the largest coal basin in the country - has been steadily increasing, reaching 220 million tons by 2020 [1], with a prospect of 320 million tons by 2030 [2 ]. In accordance with this, the annually recoverable volumes of overburden, placed in internal and external dumps, will reach 1.6 billion $\mathrm{m}^{3}$ [3-4]. As a result, the deterioration of the ecological situation in the clusters of opencast mining [5-7], along with the issues of ensuring safe labor at mining enterprises [8-9], becomes the object of the closest attention of scientists [10]. This requires a special approach to locating the internal dumps, filling which reduces the amount of overburden placed on the surface. As a result, it becomes possible to reduce the amount of dust emission and the occupation of land areas by external dumps [11-13].

The introduction of the histogram method for determining the location of the internal dump in design practice should be accompanied by an additional justification of the parameters and the area of effective application of such development systems, relative to the

\footnotetext{
* Corresponding author: sav.ormpi@,kuzstu.ru
} 
specific mining and geological and technological conditions of the existing production. In other words, along with the existing general provisions in the field of dumping, structural and parametric studies should be additionally carried out in relation to the conditions of the existing open pit.

The introduction of new spatial and planning solutions will provide a faster (operational) receipt of technological and environmental advantages of internal dumping at all mining stages due to additional dumping of one or another intermediate internal dump. Additional features detailing the process of transformation of the longitudinal deepening into the transverse mining method include the choice of the location for the construction of the reservoir for internal storage of overburden. As the most representative selection criteria, the following can be proposed:

- coal saturation (number and thickness of coal seams of the suite);

- current depth (spatial difference in elevations of the working area);

- the distance of the reservoir from the external dump (the distance of transportation of overburden rocks to the external dump at the time of construction of the reservoir);

- reservoir stripping scheme (presence of stationary and semi-stationary opening workings); - ensuring the maximum production capacity during the construction of the reservoir (share provision of the annual production capacity).

\section{Materials and Methods}

To approbate the theoretical assumptions in relation to the existing quarry field, a zoned division into sectors is made. The purpose of this approach is to determine the likely locations for the initial storage capacity for the internal dumps. In the practice of designing open pits, the main direction of development of mining operations in an open pit with deep longitudinal mining method is selected, as a rule, in relation to the most thick layer of the strata and a socalled reference axis is formed, which conventionally divides the section into two parts along the strike of the deposit. Then, conventionally, in the direction from north to south, we divide the quarry field in the plan into sections or sectors, which we assign marking: N1, N2, C1, C2, S1, D2 (Fig. 1). According to the project data, the trajectory of the direction of movement of the cut trench in the plan of the quarry field in Fig. 1 is shown with a dash-dotted line.

Regarding the longitudinal division of the opencast field, we preliminarily outline the size of the sectors based on the difference in the geometric dimensions of the opencast field plan (as shown in Fig. 1), and finally the size of the sector is chosen by enumerating the calculated values of the criteria of the proposed method. In addition to the above, such a sectoral division is necessary to clarify the following points. Firstly, to consider in detail the process of selecting a backfill for an internal dump; secondly, this is due to the unevenness of the spatial development of the quarry field; thirdly, at each of the sections, the deviation of the formation or a group of seams from straightness leads to the fact that the geometric parameters of the quarry field in the cross section can vary significantly; fourthly, the values of other calculated parameters in each sector can be very different. 


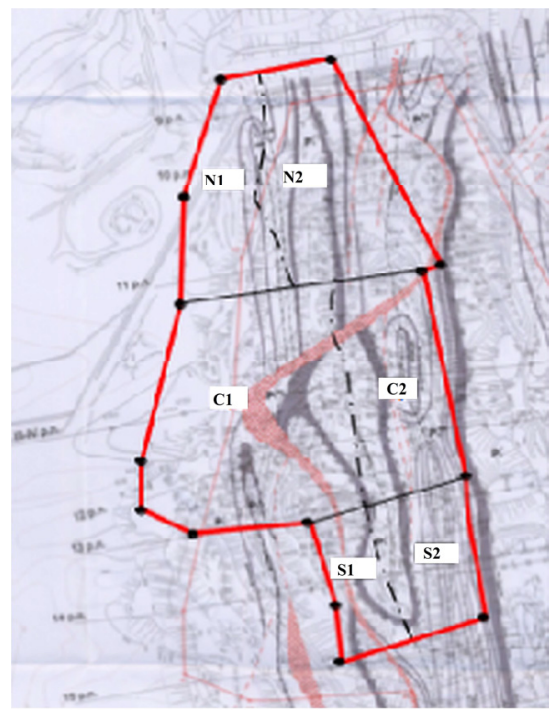

Fig. 1. Zoning of the open pit mine space in the plan into sections, when specifying the choice of the location of the reservoir for the inner dump.

\section{Results and Discussion}

Based on the design criteria presented above, the range values are established for the sectors of the quarry field (Fig. 2). Based on the totality of the proposed criteria included in the presented list, it is possible to select a sector in a quarry field, which will potentially be a storage reservoir for overburden. To clarify the choice of the sector for the internal dump, the indicators are analyzed in a complex manner, and the high or low significance of one or another factor by sector is determined from the histograms. For example, at the time of the construction of the reservoir, it is necessary to reduce the transportation distance or not to make additional cutting of the opening workings, and so on.

With regard to the conditions of the section under consideration, this will be the " $\mathrm{C} 1$ " sector, which is explained by the following calculation criteria: the number of coal seams in the sector 10 pcs (coal saturation); maximum current depth +140 meters (large capacity of the worked-out space and the smallest deepening to the design contours); the weighted average distance of transportation of overburden to the external dump is $800 \mathrm{~m}$ and the presence of a stationary stripping working (trench), the share provision of the annual production capacity is $35 \%$. Geometric parameters of the sector along the strike of the reservoir from 3-4 to 16 of the exploration lines, across the strike from the license boundaries in the selected sector to the top of the reservoir. 


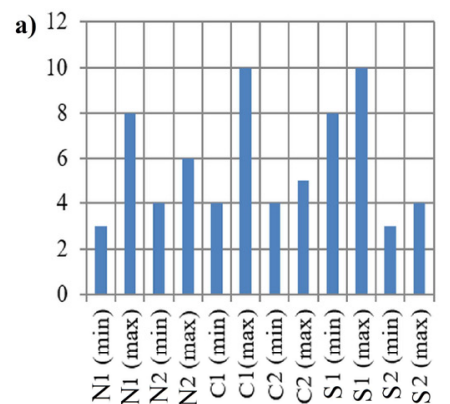

The number of coal seams by

c)
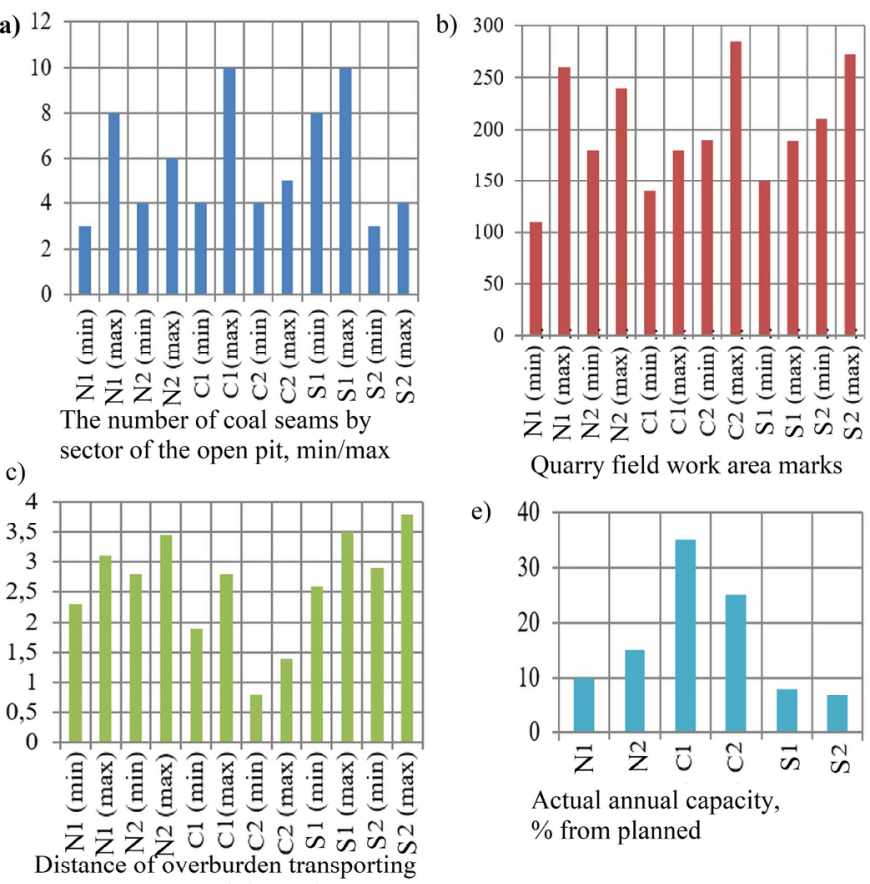

Quarry field work area marks

e)

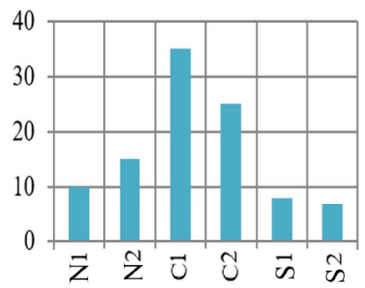

Actual annual capacity,

$\%$ from planned to external dump, $\mathrm{km}$

d)

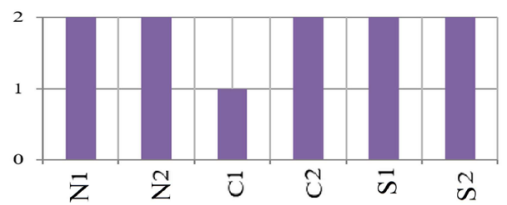

Stripping schemes (the presence of opening workings: 1-stationary; 2 -semi-stationary)

Fig. 2. Histograms for assessing the parameters of cutting the opencast field into sectors, in order to identify factors that significantly affect the choice of the location of the reservoir for the internal dump: a) the range of fluctuations in the number of coal seams in the strata; b) the maximum and minimum marks of the working area of the quarry field; c) the distance of transportation of overburden to the external dump; d) the presence of stationary or semi-stationary workings; e) share provision of annual production capacity as a percentage of the design capacity.

\section{Conclusion}

The data obtained from the results of the proposed theoretical approach (a histogram method) for determining the location of the reservoir for an internal dump in open-pit coal mining in the Kemerovo region made it possible to obtain the following conclusions. The process of gradual transformation of longitudinal deepening into transverse mining method is based on search solutions, the purpose of which is to determine the likely places for laying the initial capacity for internal dumps. The achieved technical and economic indicators of the production activity of the coal mine are regulated simultaneously with the cutting of the open pit field into sectors when choosing the location of the reservoir for the internal dump and ranking the cumulative significance of the calculated values analyzed by the histograms. 


\section{References}

1. A. Selyukov, P. Blištan, S. Jacko, V. Bauer, E3S Web of Conferences, 41, 01031 (2018)

2. V.F. Kolesnikov, J. Janočko, Journal of Mining and Geotechnical Engineering, 2, 42-74 (2020) doi: 10.26730/2618-7434-2020-2-42-74

3. S. Zhironkin, A. Selyukov, M. Gasanov, Energies, 3(13), 3305 (2020)

4. A. Selyukov, R. Rybár, E3S Web Conf. 105, 01043 (2019)

5. M. Yazevich, O. Kalinina, O.Zhironkina, E3S Web Conf. 134, 03004 (2019)

6. A.V. Selyukov, Journal of Mining Science, 51(5), 879-887 (2015)

7. T.V. Kiseleva, V.G. Mikhailov, Economics and Innovation Management, 4, 70-78 (2018) DOI: 10.26730/2587-5574-2018-4-70-78

8. D. Szurgacz, M. Tutak, J. Brodny, L. Sobik, O. Zhironkina, Energies, 13(17), 4538 (2020) DOI: 10.3390/en13174538

9. M. Tutak, J. Brodny, D. Szurgacz, L. Sobik, S. Zhironkin, Energies, 13(18), 4891 (2020)

10. M. Cehlár, P. Rybár, J. Mihók, J. Engel, Journal of Mining and Geotechnical Engineering, 1, 66-74 (2020) DOI: 10.26730/2587-5574-2020-1-66-74

11. A.V. Selyukov, Bulletin of the Tomsk Polytechnic University, Geo Assets Engineering, 326(12), 60-71 (2015)

12. A. Selyukov, V. Ermolaev, I. Kostinez, E3S Web Conf. 21, 01027 (2017)

13. A.V. Selukov, Advanced technology based on new technological and organizational principles of spatial development of front of mining operations at open pits (Taishan Academic Forum - Project on Mine Disaster Prevention and Control, 2014) 